\title{
Apoio de enfermagem ao autocuidado do cuidador familiar
}

\author{
Nursing support for self-care of family caregivers \\ Apoyo de enfermería al autocuidado del cuidador familiar
}

\author{
Sibely Rabaça Dias da Costa'; Edna Aparecida Barbosa de Castro ${ }^{\text {II }}$; Sonia Aciolill
}

\begin{abstract}
RESUMO: Este artigo apresenta uma investigação qualitativa sobre o autocuidado do cuidador familiar, cujos objetivos foram identificar os estímulos positivos e negativos que este cuidador recebe da família e analisar as necessidades de cuidados de enfermagem de acordo com estes estímulos. Com o aporte da Teoria Fundamentada nos Dados, foram entrevistados 11 cuidadores familiares de adultos e idosos dependentes de cuidados domiciliares após a alta de um hospital universitário em Minas Gerais, em 2011. Identificaram-se estímulos positivos, como a afetividade pelo membro familiar dependente e o apoio ao cuidador por outros membros da família, através dos revezamentos, e negativos, como cobranças, críticas e falta de apoio de outros familiares, incluindo o financeiro. Concluiu-se que uma rede de apoio formal se faz necessária seja pela estratégia saúde da família seja pelo serviço de atenção domiciliar para apoiar e/ou suprir as dificuldades encontradas pelos cuidadores familiares que apresentam uma rede de apoio familiar insuficiente.
\end{abstract}

Palavras-Chave: Cuidadores; família; enfermagem; autocuidado.

\begin{abstract}
This article presents a qualitative study of self-care for family caregivers. Its main goals were to identify the positive and negative stimuli that such caregivers receive from their families, and to examine the nursing care needs posed by these stimuli. Taking Grounded Theory as a framework, 11 family caregivers of adults and older adults dependent on home care after discharge from a university hospital in Minas Gerais were interviewed in 2011. Positive stimuli identified included affection towards the dependent family member, and other family members' support by taking turns in providing care. Negative stimuli were demands, criticism and lack of support, including financial support, from other family members. It was concluded that there is a need for a formal support network to be provided either by the Family Health Strategy or by the home care service in order to support family caregivers with insufficient family support networks, and/or help them overcome the difficulties they face. Keywords: Caregivers; family; nursing; self-care.
\end{abstract}

RESUMEN: Este artículo presenta una investigación cualitativa sobre el autocuidado del cuidador familiar, cuyos objetivos fueron identificar los estímulos positivos y negativos que el cuidador recibe de la familia y analizar las necesidades de cuidados de enfermería de acuerdo a estos estímulos. Con el aporte de la Teoría Fundamentada en los Datos, se han entrevistado 11 cuidadores familiares de adultos y ancianos dependientes de cuidados domiciliarios después del alta de un hospital universitario en Minas Gerais, en 2011. Se identificaron estímulos positivos: la afectividad por parte del miembro familiar dependiente y el apoyo al cuidador por parte de otros miembros de la familia a través de turnos; y negativos: demandas, críticas y falta de apoyo de otros familiares, incluso apoyo financiero. Se concluyó que una red de apoyo formal se hace necesaria, ya sea por la estrategia de salud de la familia o por el servicio de atención domiciliaria para apoyar y/o ayudar en las dificultades encontradas por los cuidadores familiares que presentan una red de apoyo familiar insuficiente.

Palabras Clave: Cuidadores; familia; enfermería; autocuidado.

\section{INTRODUÇÃO}

No final do século XX, o Brasil passou por mudanças demográficas e epidemiológicas com significativa diminuição das taxas de fecundidade, natalidade e aumento progressivo da expectativa de vida, apresentando um aumento da proporção do número de idosos em relação aos demais grupos etários, além de mudanças no perfil de morbidade e mortalidade do país, caracterizado pelo aumento das doenças crônicas ${ }^{1}$.
Segundo dados do Instituto Brasileiro de Geografia e Estatística (IBGE), as mudanças quanto ao padrão de organização das famílias nos países industrializados vêm se refletindo no Brasil a partir das duas últimas décadas do século XX, através das reduções do tamanho da família e do número de casais com filhos, como resultado dos processos de declínio da fecundidade e do aumento da expectativa de vida².

IEnfermeira. Mestre em Enfermagem pela Faculdade de Enfermagem da Universidade Federal de Juiz de Fora. Pesquisadora integrante do Grupo de Estudos e Pesquisas em Autocuidado e Processo Educativo em Saúde e Enfermagem da Universidade Federal de Juiz de Fora. Minas Gerais, Brasil. E-mail: sibelydemoraes@yahoo.com.br.

IIEnfermeira. Doutora em Saúde Coletiva. Professora Adjunta do Departamento de Enfermagem em Saúde do Adulto da Faculdade de Enfermagem da Universidade Federal de Juiz de Fora. Líder do Grupo de Estudos e Pesquisas em Autocuidado e Processo Educativo em Saúde e Enfermagem. Juiz de Fora, Minas Gerais, Brasil. E-mail: edna.castro@ufjf.edu.br.

IIIEnfermeira. Doutora em Saúde Coletiva. Professora Adjunta do Departamento de Enfermagem em Saúde Pública da Faculdade de Enfermagem da Universidade do Estado do Rio de Janeiro. Brasil. E-mail: soacioli@gmail.com. 
De acordo com esses dados, pressupõe-se que, mediante a diminuição do número de integrantes da família, quando um membro dessa família fica doente e se torna dependente, as necessidades de cuidados não serão devidamente atendidas, e haverá uma sobrecarga sobre aquele membro que se dispuser a assumi-las. Dessa forma, o estudo aborda o autocuidado do cuidador familiar que precisa ser conciliado com os cuidados de seu familiar dependente, necessitando de apoio para o aprendizado e/ou realização para evitar o déficit do autocuidado.

O presente artigo constitui-se em um capítulo de uma dissertação cujo objeto foi o autocuidado do cuidador familiar que, nesse contexto, sofre influências de acordo com os estímulos recebidos pelo restante da família ${ }^{3}$. Assim, os objetivos foram identificar os estímulos positivos e negativos que um cuidador familiar de adultos ou idosos dependentes no domicílio recebe da família, e analisar as necessidades de cuidados de enfermagem de acordo com estes estímulos, considerando a Teoria de Enfermagem de Dorothea Orem.

\section{REVISÃo DE LITERATURA}

O autocuidado é o cuidado pessoal que as pessoas realizam diariamente para regular o próprio funcionamento de vida e desenvolvimento humano, sendo uma função humana regulamentar. Trata-se de um conceito chave da Teoria Geral de Dorothea Orem, que expressa e desenvolve a razão pela qual as pessoas, que se encontram em déficit de autocuidado, necessitam da enfermagem. A Teoria do Déficit de Autocuidado engloba a Teoria dos Sistemas de Enfermagem, que identifica a demanda de autocuidado que pode ser parcial, total ou apenas a necessidade de apoio-educação da enfermagem ${ }^{4}$.

Observa-se no interior das famílias a existência de uma rotina de revezamentos entre os cuidadores familiares ou mesmo uma hierarquização do conjunto de ações e cuidados demandados. Todavia, quando é pequeno o número de pessoas na família, tal revezamento ou hierarquização não se efetiva, acentuandose a sobrecarrega do membro cuidador, o que prejudica seu autocuidado 5 .

No contexto do cuidado à saúde, alguns autores referem-se à família como sendo uma instituição social que se encontra limitada ao grupo de pessoas relacionadas por alianças de sangue, casamento ou união estável. Outros, todavia, apresentam uma visão ampliada acerca do termo família, incluindo as pessoas com fortes laços sociais como uma base adequada e orientadora das ações e cuidados de enfermagem ${ }^{4}$. No contexto assistencial atual, compreender as funções da família é importante no processo de trabalho do enfermeiro, e o reconhecimento da demanda de autocuidado terapêutico de cada membro da família se faz necessário para o desenvolvimento de estratégias para atender a essas demandas.
O cuidar pressupõe o atendimento às necessidades que se encontram afetadas tanto pelo familiar dependente quanto pelo cuidador. Embora não sejam evidenciadas, tais necessidades demandam atenção e cuidados contínuos em decorrência da sobrecarga física e psicológica que a este cuidador se submete ${ }^{6}$.

Ao estudar a capacidade de autocuidado de adultos e idosos hospitalizados, observou-se que quanto menor a capacidade de autocuidado do familiar dependente, maior a necessidade de apoio de um cuidador familiar, o que poderá sobrecarregá-lo, necessitando que o enfermeiro identifique esses cuidadores para o planejamento de praticas educativas que possam dar continuidade ao autocuidado após a alta hospitalar?.

É importante destacar que a sobrecarga do cuidador não está relacionada somente a questões objetivas, decorrentes do ato de cuidar, mas também a questões subjetivas relacionadas a conflitos familiares e mudanças na rotina do cuidador, como o abandono do trabalho e deficiência de lazer, por exemplo ${ }^{8}$. Essa sobrecarga também está relacionada com um suporte social insuficiente, a dificuldade do paciente na realização de tarefas rotineiras, a insatisfação do cuidador com o apoio recebido de parentes ou amigos, o excesso de trabalho, e está mais presente no discurso de famílias que têm uma rede de suporte deficiente9.

A estrutura das relações sociais é composta pela rede de relações formais (através da assistência de profissionais) e informais (através do auxílio de amigos e familiares), sendo que o apoio social compreende recursos fornecidos em quatro âmbitos: apoio emocional; apoio instrumental; apoio de informações e interação social ${ }^{10}$.

Dessa forma, as intervenções da equipe de saúde devem ser direcionadas na busca de apoio social, como estratégia de se preservar tanto a saúde do cuidador quanto o processo de reabilitação do doente, através de ações que contribuam para que o familiar retome seu plano de vida abandonado ao se constituir cuidador ${ }^{10}$.

\section{Metodologia}

Optou-se pela Teoria Fundamentada nos Dados (TFD) como abordagem metodológica para a compressão do fenômeno em tese, sobretudo por ser um tipo de pesquisa qualitativa cujas raízes se encontram no Interacionismo Simbólico, que permite descrever uma teoria que é derivada de dados coletados em cenários naturais, reunidos e analisados sistematicamente através das suas etapas de coleta de dados, codificação, análise e teoria ${ }^{11}$.

A coleta de dados foi realizada em duas etapas: primeiramente em um Hospital Universitário (HU) no interior de Minas Gerais, onde cuidadores familiares de adultos e idosos dependentes foram selecionados, através da busca ativa nos prontuários e visita de enfermagem nas clínicas médica feminina e masculina, no primeiro trimestre de 2011. Em um segundo momento, 
o ambiente domiciliar, onde os cuidadores relacionavam-se com o membro familiar dependente após a alta, passou a ser o cenário principal do estudo, utilizando-se da estratégia da visita domiciliar (VD), observações e registros em diário de campo, além de uma entrevista semiestruturada com cada cuidador.

Como critérios de inclusão na pesquisa, foram considerados: adultos (a partir de 18 anos), residentes no município sede do estudo e que se caracterizassem como um cuidador familiar de um adulto ou idoso que apresentasse dependência para os cuidados e necessitasse de auxilio contínuo. $O$ número de cuidadores foi definido através do processo de amostragem por saturação teórica. Dessa forma, foram selecionados 11 cuidadores familiares com os seguintes graus de parentesco: quatro filhas, uma esposa, dois maridos, dois sobrinhos e duas mães, sendo oito cuidadores do gênero feminino e três cuidadores do gênero masculino, com idades variando entre 22 e 66 anos.

A pesquisa exploratória iniciou-se após a aprovação do Comitê de Ética do HU da Universidade Federal de Juiz de Fora (UFJF), com número de protocolo 103-4202010, seguindo os critérios que regulamentam os aspectos ético-legais de pesquisas envolvendo seres humanos ${ }^{12}$. Um Termo de Consentimento Livre e Esclarecido foi elaborado, explicado e assinado por todos os participantes do estudo e suas identidades foram preservadas através do uso de pseudônimos.

A coleção de dados foi importada para o software OpenLogos (versão 1.0.2) ${ }^{13}$. Esse programa possibilitou a organização e codificação dos dados, facilitando o desenvolvimento das categorias. A análise dos dados na TFD ocorre através das codificações aberta, axial e seletiva, em que os dados são codificados, conceitualizados e agrupados de acordo com suas similaridades para a construção das categorias do estudo.

O presente artigo apresenta a categoria Estímulos ao autocuidado do cuidador quando o contexto de cuidado é a família, com suas duas subcategorias relacionadas: Estímulos positivos: acolhimento, interações afetivas e apoio no interior da família, e Estímulos negativos: acusações, cobranças e negação de apoio por outros membros da família.

\section{Resultados e Discussão}

Na medida em que o cuidador assumia a diretriz do cuidado de seu familiar dependente no domicílio, o autocuidado sofria influências conforme os estímulos do restante da família. As duas subcategorias emergentes dos discursos são analisadas a seguir.

\section{Estímulos positivos: acolhimento, interações afetivas e apoio no interior da família}

Observou-se ao longo do trabalho de campo que, quando o cuidador recebia apoio e era acolhido no seio familiar, ele desenvolvia o seu papel com mais estímulo e motivação, referindo-se à menor sobrecarga. A expectativa de melhora das condições de vida da família se constituiu em um desses estímulos, através da esperança do cuidador em encontrar melhores condições de acesso aos cuidados para o familiar dependente, além da expectativa de melhora do quadro clínico deste familiar. Assim, os cuidadores teriam menos sobrecarga no cuidado do familiar, além de mais tempo para o autocuidado, o que pode ser analisado pelas falas:

[...] Eu conseguindo tudo o que ela necessita para eu cuidar dela em casa direito, eu creio que daí então eu vou poder ter um tempo para viver melhor. Porque vai acabar esse trajeto de idas e voltas, [...] eu vou ter a visita de enfermeiros em casa. (Lílian/filha)

Eu aposentei e depois disso eles [patrões]: Ó, se quiser voltar. Eu falei: Não, deixa Deus ajudar que, quando ela pegar saúde completa, que então não precisa de eu estar aqui no dia a dia. (Ivo/marido)

Dessa forma, quando havia essa expectativa de melhora, o cuidador desenvolvia uma esperança que o impulsionava a continuar buscando melhores condições de vida e cuidado para o familiar dependente, através de recursos que facilitassem o cuidar.

Identificou-se, também, a existência de afetividade do cuidador pelo membro familiar dependente. Notou-se que, quando havia sentimentos de amor e de afeto, emanados pelos cuidadores ao cuidar do familiar dependente e demonstrados por meio de atitudes, expressões e gestos simbólicos, os cuidadores não associavam o processo de cuidar a sofrimento ou queixas de tensão ou sobrecarga, mas a um prazer e satisfação em cuidar.

Eu vejo muita vantagem porque eu penso assim, a educação que ela deu para a gente, é a resposta que nós estamos dando hoje para ela [...]. Então a dificuldade está aí, mas esse trabalho que a gente faz com a mãe nossa, ele não tem preço, só tem amor, só amor, mais nada. (Isabel/filha)

É bem gratificante, porque eu acho que mesmo ela estando no estado que ela está, só pelo fato dela estar aqui, já dá motivação para eu fazer tudo que eu puder fazer. (Lara/filha)

Assim, os laços de afeto entre o cuidador e o familiar dependente se constituem em um estímulo positivo que facilita a realização dos cuidados. A relação de afetividade entre o cuidador e o membro familiar dependente foi presenciada em todas as famílias visitadas.

Dessa forma, os cuidadores avaliam sua relação com o receptor de cuidados como caracterizada por forte vínculo de afeição, toleram melhor o ônus do cuidado e evidenciam menos tensão, o que desperta o desejo de prestar assistência, independente da obrigação ${ }^{14}$.

Outro estimulo que se configurou em apoio ao autocuidado do cuidador foi o comportamento zeloso do cuidador pelo familiar dependente, demonstrado 
com atitudes de preocupação quanto ao atendimento das necessidades dele, o que pode ser observado através do depoimento:

Eu um dia falei com a mãe: Ó mamãe, se tivesse uma coisinha, mais uma coisinha, onde quer que fosse, que eu pudesse te ajudar para melhorar a senhora, eu iria. Ela falou assim: Eu sei que vocêfaz o que pode. (Marta/filha)

Este comportamento zeloso favorecia o relacionamento entre o cuidador e o familiar dependente, o que proporcionava um alívio nas situações estressantes e minimizava a sobrecarga do cuidador.

$O$ apoio ao cuidador por outros membros da família, incluindo os apoios físico, emocional e financeiro por parte de outros membros ou pessoas significativas da família, também se constituiu em um estímulo positivo relevante no contexto de autocuidado do cuidador. Evidenciou-se que, quando recebiam apoio de outros membros, por menor que fosse, os cuidadores ressaltavam que a rotina dos cuidados fluía mais facilmente, sem sobrecargas. Reforçavam que durante o revezamento nos cuidados conseguiam tempo para realizar o autocuidado. Essa modalidade de apoio foi observada em apenas quatro dos 11 cuidadores estudados e pode ser analisada a partir dos depoimentos:

Eu tenho que trabalhar, ele trabalha [esposo]. Às vezes, por exemplo, eu vou parar oito horas e ele vai pegar às seis horas, sete horas, aí ele ficou [irmão do esposo]. Sábado ele ficou aqui. Ele fica, não reclama não. Mas se for para ficar todo dia, não fica também não. A responsabilidade é nossa. Nós é que pegamos. (Elisa/sobrinha)

Por enquanto, está dando para a gente ir levando, porque a colega dela vem de vez em quando aqui, então eu saio para fazer minhas coisas. (Ivo/marido)

Tomando como referência o constructo teórico de Orem, ao abordar o autocuidado do cuidador domiciliar, apreende-se que, mediante o suporte de uma rede social de apoio informal, instala-se o sistema de enfermagem de apoio-educação, em que o cuidador tem capacidade e disponibilidade de aprender habilidades e o enfermeiro irá orientá-lo no desenvolvimento de sua função ${ }^{4}$.

Em um estudo sobre a qualidade de vida do cuidador do portador de Doença de Alzheimer, ao avaliar o domínio das relações sociais, as autoras constataram que os cuidadores que recebiam apoio no cuidado evidenciavam melhor qualidade de vida, o que mostra a importância da elaboração de estratégias pelos profissionais para suprir a falta de apoio e diminuir o processo de adoecimento e exaustão por parte do cuidador ${ }^{15}$.

O enfermeiro deve lançar mão de práticas educativas, dentro de uma proposta de construção compartilhada entre o saber científico e o saber popular, através do planejamento das ações a partir da realidade, dos interesses e das necessidades identificadas, a fim de promover a autonomia e a cidadania dos sujeitos ${ }^{16}$.

\section{Estímulos negativos: acusações, cobranças e ne- gação de apoio por outros membros da família}

Quando o cuidador não recebia apoio de amigos ou familiares e, ainda, havia cobranças e acusações vindas de outras pessoas externas ao binômio cuidador familiar-familiar dependente, o cuidador se tornava sobrecarregado e apresentava um desgaste físico e psicológico que precisava ser amenizado através de cuidados sistematizados pelo enfermeiro.

Um dos estímulos negativos encontrado foi a falta de compreensão de outros familiares, presenciado quando havia discordância de outros membros da família quanto às atitudes do cuidador familiar em relação ao cuidado com o familiar dependente, o que pode ser analisado a partir dos relatos:

A família do pai deles [...] são pessoas muito difíceis, são pessoas com a cabeça muito dura. Então tudo que vocêfala, você fala uma coisa, você acha que eles estão entendendo, mas eles não estão entendendo nada[...]. Elas acham fácil. Pega isso aí e faz, mas elas não vão lá pra saber o custo daquilo, o que eu gastei de passagem para ir e para voltar. (Eva/mãe)

Tudo o que é prioridade é o que vem das outras partes, sabe. O que vem das outras partes é prioridade, das minhas não [...]. Porque não é fácil. Você arcar sozinha, 24 horas por dia com uma pessoa idosa sob a sua total responsabilidade. Se der tudo certo, você não recebe louro não, mas se houver uma pequena falha, você vai ser condenada pelo resto da vida por aquele deslize. (Marta/filha)

Notou-se, nas situações evidenciadas, que os outros componentes da família não compreendiam a demanda do cuidador, e esta cobrança, revestida de desconfiança e críticas, gerava um quadro de sobrecarga emocional. Acrescenta-se a essa cobrança uma vigilância contínua, inerente à sentida responsabilidade pela condição de estar diretamente envolvido com as ações de cuidado do familiar dependente, o que foi observado através das falas:

A hora que ela caiu, a primeira vez, foi com ele [esposo]. Se fosse comigo, ele iria me xingar. Porque iria falar que eu não olhei, que isso e aquilo. [...] Porque, por mais que a gente faça, por mais que você olhe, sempre tem um para falar. Para ajudar não tem não, mas para falar tem. (Elisa/sobrinha)

Tem alguma coisa mais que eu possa fazer? O que eu posso fazer para melhorar? A gente está sempre perguntando se o que a gente está fazendo está certo, se aquilo vai ajudá-la, em que vai ajudar, o que a gente pode fazer mais. (Marta/filha)

Neste caso, a cuidadora se autocobrava e não considerava que os cuidados realizados estavam adequados ou eram suficientes para suprir as demandas do familiar dependente, numa constante vigília ou busca de perfeição em atitudes preventivas aos ataques ou críticas advindas. 
Outro estímulo negativo encontrado foi a falta de apoio de outros familiares, presenciada quando o cuidador não encontrava em outros membros da família ajuda financeira ou auxílio para revezar nos cuidados com o familiar dependente, o que o deixava sobrecarregado, dificultando a realização do autocuidado.

Porque ninguém tem tempo para vir para cá. Outras desculpas existem, porque na cabeça dessas outras pessoas, o que elas têm é mais importante do que eu tenho[...]. (Marta/filha)

Eu acho que pelo menos se o pai ficasse com ele de 15 em 15 dias porque, por mais que eu faça, eu acho que eu merecia o direito de eu ter pelo menos um final de semana para cuidar de mim ou durante a semana que eu pudesse ir ao médico, que eu pudesse fazer qualquer coisa, mas que eu saísse daquele estresse. (Eva/mãe)

A falta de apoio, nas famílias pesquisadas, não se referia somente à ajuda física de outro familiar na execução de cuidados, mas também ao apoio financeiro em decorrência do aumento das despesas com os cuidados do familiar dependente.

De repente ter que parar tudo assim, ficar cuidando de casa, porque você é obrigado. Porque você vê, a filha não ajuda, o filho também é desse jeito, então, queira ou não queira eu sou obrigado a cuidar. (Saulo/marido)

Não recebo ajuda de ninguém não. De marido que já morreu, não tive pensão, não tive nada. E ele também, coitado, ele ajuda assim, de eu estar aqui. Mas, ele não pode também, às vezes, me ajudar. Igual eu estou precisando tratar os dentes e fica caro. Porque ele também ganha pouco, um salário mínimo. (Gisele/esposa)

Assim, os cuidadores apresentavam dificuldades financeiras não só pelo aumento das despesas com o cuidado do familiar dependente, mas também pela falta de apoio de outros familiares.

No contexto do cuidado de enfermagem ao cuidador que se encontra em condição de desgaste ou tensão, quando não se observa a existência de uma rede social de apoio informal, do ponto de vista de Dorothea Orem, deve ser utilizado o sistema de enfermagem totalmente compensatório, aquele em que o enfermeiro deverá suprir, de forma integral, os cuidados de que o cuidador familiar necessita ${ }^{4}$.

Um artigo sobre estudos nacionais de cuidadores familiares de idosos mostrou que o estresse do cuidador era causado pela sobrecarga de cuidados, por ser cuidador único e por tempo prolongado, pela imposição da tarefa de cuidar, pela percepção negativa do cuidado, pelo isolamento social, alem da precária situação econômica. Os estudos indicaram, ainda, a necessidade de o enfermeiro estabelecer um vínculo terapêutico, através de um suporte educacional, social e psicológico com essas famílias, e identificar suas necessidades para traçar estratégias de cuidado que proporcionassem alívio do estresse, organização e sistematização do cuidado e suporte social para melhorar a qualidade de vida desses cuidadores ${ }^{17}$.

Portanto, programas de suporte formal devem ser incentivados para promover o equilíbrio familiar, favorecer a redução de conflitos e fornecer aos cuidadores familiares uma referência profissional para orientá-los, capacitá-los e favorecê-los na conciliação do autocuidado com os cuidados do familiar dependente. Dois exemplos de programas que podem ser utilizados, são ofertados pelo Sistema Único de Saúde, a estratégia saúde da família (ESF), através da realização de visitas domiciliares periódicas ${ }^{18}$ e o serviço de atenção domiciliar (SAD), reunido em três modalidades de atenção, de acordo com o perfil do familiar dependente ${ }^{19}$.

\section{Conclusão}

A abordagem metodológica utilizada, através de suas fases de coleta de dados, codificação e análise, permitiu a compreensão do apoio de enfermagem ao autocuidado do cuidador familiar, tomando como base os estímulos recebidos pelo restante da família.

A utilização das Teorias de Dorothea Orem mostrou que a demanda dos cuidados de enfermagem pelo cuidador familiar aumenta na medida em que são encontrados estímulos negativos como a falta de apoio e compreensão e a cobrança, que comprometem tanto o cuidado do familiar dependente quanto o autocuidado do cuidador.

A limitação do estudo está no fato de terem sido investigados cuidadores familiares de apenas um município de Minas Gerais. Dessa forma, são necessários avanços na investigação de cuidadores familiares de outras regiões do país, para a realização de estudos comparativos, por se entender que se trata de um grupo crescente no contexto do cuidado domiciliar, sobretudo aliado à mudança do perfil demográfico e epidemiológico da população brasileira.

Conclui-se que uma rede de apoio formal se faz necessária e pode ser implementada através da ESF e do SAD para apoiar e/ou suprir as dificuldades encontradas pelos cuidadores familiares que apresentam uma rede de apoio familiar insuficiente. Ao auxiliar e prestar cuidados ao familiar dependente no domicílio, o enfermeiro estará colaborando tanto para a capacitação do cuidador, quanto para uma assistência integral a partir do momento em que a família também é envolvida em seu plano de cuidados. E ao cuidar da família, de forma integral, o enfermeiro estará colaborando para a prevenção do adoecimento dos cuidadores familiares.

\section{REFERÊNCIAS}

1.Ministério da Saúde $(\mathrm{Br})$. A vigilância, o controle e a prevenção das doenças crônicas não transmissíveis: DCNT no contexto do Sistema Único de Saúde brasileiro. Brasília (DF): Ministério da Saúde; 2005. 
2.Instituto Brasileiro de Geografia e Estatística. Síntese de indicadores sociais: uma análise das condições de vida da população brasileira 2010. Rio de Janeiro: IBGE; 2010. 3.Costa SRD. Autocuidado do cuidador familiar de adultos ou idosos dependentes após a alta hospitalar: uma contribuição para o cuidado de enfermagem [dissertação de mestrado]. Juiz de Fora (MG): Universidade Federal de Juiz de Fora; 2012.

4.Orem DE. Nursing: concepts of practice 5th ed. St. Louis (Mis): Library of Congress; 1995.

5.Castro EAB. Tecendo a rede de proteção após a queda: o cuidado depois da alta. In: Camargo Junior KR. Por uma filosofia empírica da atenção à saúde: olhares sobre o campo biomédico. Rio de Janeiro: Fiocruz; 2009. p. 155-87.

6.Gomes WD, Resck ZMR. Cuidado a clientes com sequelas neurológicas. Rev enferm UERJ. 2009; 17: 496-501.

7.Costa SRD, Castro EAB. Acioli S. Capacidade de autocuidado de adultos e idosos hospitalizados: implicações para o cuidado de enfermagem. Rev Min Enferm. 2013; 17(1):193-207.

8.Pedreira LC, Oliveira MAS. Cuidadores de idosos dependentes no domicílio: mudanças nas relações familiares. Rev Bras Enferm. 2012; 65: 730-6.

9.Brito ES, Rabinovich EP. A família também adoece!: mudanças secundárias à ocorrência de um acidente vascular encefálico na família. Interface - Comunic, Saúde, Educ. 2008; 12:783-94.

10.Bocchi SCM, Angelo M. Entre a liberdade e a reclusão: o apoio social como componente da qualidade de vida do binômio cuidador familiar-pessoa dependente. Rev Latino-Am Enfermagem. [online]. 2008; 16(1). [citado em 05 abr 2013]. Disponível em: http://www. scielo.br/pdf/rlae/v16n1/pt_02.pdf.

11.Strauss A, Corbin J. Pesquisa qualitativa: técnicas e procedimentos para o desenvolvimento de teoria fundamentada. 2a ed. Porto Alegre (RS): Artmed; 2008.

12. Ministério da Saúde (Br). Conselho Nacional de Saúde. Resolução no 196, de 10 de outubro de 1996 [online]. Aprova as diretrizes e normas regulamentadoras de pesquisas envolvendo seres humanos [citado em 30 jul 2011]. Disponível em: http://bvsms.saude.gov.br/bvs/ saudelegis/cns/1996/res0196_10_10_1996.html.

13.Camargo Junior KR. Apresentando Logos: um gerenciador de dados textuais. Rio de Janeiro: Instituto de Medicina Social, UERJ; 2003.

14.Fernandes MGM, Garcia, TR. Determinantes da tensão do cuidador familiar de idosos dependentes. Rev Bras Enferm. 2009; 62:57-63.

15.Bagne BM, Gasparino, RC. Qualidade de vida do cuidador do portador de Doença de Alzheimer. Rev enferm UERJ. 2014; 22:258-63.

16.Acioli S, David HMSL, Faria MGA. Educação em saúde e a enfermagem em saúde coletiva: reflexões sobre a prática. Rev enferm UERJ. 2012; 20:533-6.

17. Oliveira DC, D’Elboux MJ. Estudos nacionais sobre cuidadores familiares de idosos: revisão integrativa. Rev Bras Enferm. 2012; 65:829-38.

18.Ministério da Saúde (Br). Saúde da família: uma estratégia para a reorientação do modelo assistencial. Brasília (DF): Ministério da Saúde; 1997.

19.Ministério da Saúde (Br). Secretaria de Atenção à Saúde. Portaria no 963, de 27 de maio de 2013. Brasília (DF): Gabinete Ministerial; 2013. 